\title{
Políticas Públicas e Inclusão: Análise e Perspectivas Educacionais
}

\author{
Public Policies and Inclusion: Analysis and \\ Educational Perspectives
}

Neli Klix Freitas ${ }^{1}$

\section{RESUMO}

A proposta do artigo é a de apresentar percursos de Políticas Públicas Inclusivas, questões teóricas e conceituais sobre a temática da inclusão, permeando estes temas com questionamentos e reflexões sobre o tema da educação inclusiva e da inclusão sócio-educativa. $\mathrm{O}$ direito ao ensino regular tem possibilitado às crianças com necessidades educativas especiais o desenvolvimento de funções cognitivas e sociais, que resultam em aprendizagens significativas. Estas aprendizagens envolvem tanto os professores, quanto os alunos com necessidades educativas especiais, envolvidos nesse processo. O artigo também problematiza pontos de vista diferentes sobre políticas públicas para a inclusão, apontando para a necessidade de revisão de paradigmas em educação e na vida em sociedade. Palavras-Chave: Políticas Públicas; Educação Inclusiva. Necessidades Educativas Especiais; Interação Social.

\begin{abstract}
This article explores and discusses inclusive educational policies, and also theorectical questions and reflections about inclusive education and social inclusion. The right to regular education has made possible for children with special educational needs development cognitive and social functions, witch results in important learning. This process involves both teachers and students with special educational needs. The article also focuses different discussion about inclusive educational policies and suggests a revision of paradigms in education and society about inclusive questions.
\end{abstract}

Keywords: Public Policies; Inclusive Education; Special Educational Needs; Social Interaction. 


\section{Introdução}

Nas diferentes áreas do conhecimento, a literatura assinala para grandes transformações educacionais: mudanças nos parâmetros curriculares nacionais, na legislação referente à acessibilidade à escola, mudanças na obrigatoriedade do ensino, na fundação de outro tipo de escola. Existe o direito universal à educação e à escola para todos os brasileiros, assim como as escolas brasileiras têm a obrigatoriedade legal de acolher a todos. A abertura das escolas para as diferenças é, principalmente, uma decorrência da legislação e, com base na mesma, de políticas públicas, o que implica em uma mudança radical nos processos de ensino e aprendizagem. Inclui uma proposta de ruptura entre as fronteiras existentes em diferentes disciplinas, entre saber e realidade. Trata-se de uma valorização da multiplicidade, da integração de saberes, das redes de conhecimento que, a partir daí se formam e se constituem. Assinala para a transversalidade das áreas curriculares e para a autonomia intelectual do aluno, sujeito do conhecimento e que, por isso mesmo, imprime valor ao que constrói. Esse processo não pode prescindir da interação social.

É importante refletir sobre os impactos das ações emanadas de políticas públicas para professores e alunos, em se tratando de educação inclusiva.

Muitas vezes, o educador se vê na posição de regular os desejos dos educandos com ou sem necessidades educativas especiais, na escola inclusiva. Necessita decidir entre o prazer e a atividade intelectual para a qual é convocado, entre espaços tabu e o cotidiano, entre o prazer e a racionalidade. Entretanto, a legislação assinala que o professor deve dominar suas restrições pessoais às diferenças, aliadas com domínios metodológicos e conhecimentos pedagógicos capazes de dar conta das distintas necessidades de seus alunos. É uma questão que desponta como realidade, vinculada à aceitação incondicional das diferenças entre as pessoas. Remete a uma maior reflexão sobre o que realmente significa aprender, quem aprende e como se aprende.

As implicações da educação inclusiva para os educadores incluem a construção de uma pedagogia da diferença, que não realce o exotismo, nem endemoninhe o outro, mas que busque definir e conhecer a diferença tanto em sua especificidade, quanto em sua capacidade de formar posições para relações sociais e práticas culturais politicamente engajadas, ao estimular e valorizar a aprendizagem da criança como um ser que imagina e cria.

Nesse contexto ainda recente o que se espera dos professores é uma postura de aceitação da proposta inclusiva em educação, com atitudes de engajamento, de acolhimento à diversidade com abertura para exercitar práticas inovadoras em sala de aula. Novas propostas pedagógicas coincidem com o conhecimento da legislação vigente, envolvem conteúdos e práticas que exercitem a criatividade. Mas é importante adotar uma postura crítica sobre a complexa trama existente entre políticas públicas, legislação, educação e sociedade, ao falar sobre inclusão e sobre diversidade.

\section{Políticas Públicas, Legislação e Aportes Teóricos: Tramas e Desafios.}

Após inúmeras pressões políticas, sociais e educativas, atualmente tem-se medidas legislativas que atestam o direito às pessoas com necessidades educativas especiais de freqüentarem as instituições de ensino, fato que cresce a cada dia. Conforme a Organização das Nações Unidas para a Educação, a Ciência e a Cultura (UNESCO), o Brasil é o país da América Latina que mais insere alunos com necessidades especiais em escolas regulares, seguido de México e Chile (Boletim da UNESCO, 1998). Examinando a legislação de vários países do mundo, como o artigo 26 da Declaração Universal dos Direitos Humanos (1948), a Convenção dos Direitos da Criança (1989) e as Diretrizes da Primeira Conferência Mundial sobre a Educação, reunida em Jomtien, Tailândia (1990); o Fórum Mundial sobre a Educação, realizado em Dakar, Senegal (2000), o Estatuto da Criança e do Adolescente (Lei 8069/90), dentre outras, é possível evidenciar o que consta sobre a educação, como sendo um direito humano inalienável, que proporciona aos cidadãos o conhecimento necessário para viver com dignidade. Há unanimidade nas questões econômicas, sociais, políticas, culturais e sanitárias de que não haverá desenvolvimento expressivo 
nestes setores, sem um investimento na educação (BIANCHETTI, 1995).

Investir em educação constitui a primeira etapa indispensável para assegurar os direitos humanos, tais como a postura de aceitação das desigualdades e da diversidade, a redução da pobreza, a aceitação de avanços na saúde e nutrição, o controle de crescimento demográfico, dentre outros.

Ao longo da história, o cenário, particularmente no que se refere às pessoas com necessidades especiais nem sempre foi o de aceitação das desigualdades. Até meados do século XVIII algumas práticas eram executadas com estas pessoas, tais como abandono, afogamentos, asfixia. Ao final do século XVIII e nas três primeiras décadas do século XIX teve início, nos países escandinavos e na América do Norte, o período de institucionalização especializada de pessoas com deficiências, nomenclatura adotada na época. A partir daí surgiu a Educação Especial. A sociedade tomou consciência da necessidade de atender as pessoas denominadas como deficientes, mas a forma de atendimento priorizava um caráter assistencialista. A assistência era prestada em Centros Especializados, nos quais as pessoas recebiam atendimento de vários profissionais: médicos, psicólogos, psicopedagogos, assistentes sociais.

No século XX, a desinstitucionalização começa a ocorrer com programas escolares para deficientes mentais. Os serviços especiais foram diversificados e as classes especiais passaram a integrar o contexto escolar. No Brasil, as classes especiais foram criadas entre 1960 e 1965, em todo o país, para pessoas excepcionais. Este era o termo empregado exclusivamente para as pessoas que freqüentavam as classes especiais. Estas classes especiais contribuíram novamente para a segregação e exclusão. A partir de 1980, esta terminologia deficiente foi alterada para pessoas portadoras de deficiência. A partir de 1986 houve a substituição de pessoas portadoras de deficiência, bem como de excepcionais, específica das classes especiais, para pessoas com necessidades educativas especiais. Mas, a adoção desta terminologia foi um processo lento. Ainda hoje em dia é possível ouvir referências aos deficientes, aos excepcionais, apesar da existência legal das nomenclaturas oficiais. Tal questão pode ser atribuída à lentidão na aceitação real da educação inclusiva e nas resistências às mudanças no cotidiano da educação (CARDOSO, 2003).

Revendo a obra de Diniz e Guilhem (2007) sobre as mudanças na terminologia, pode-se associar o termo deficiente com o modelo médico vigente nas primeiras décadas do século passado. Ao adotar a terminologia necessidades educacionais especiais, fica presente a dimensão que evolui do indivíduo para uma concepção social, onde a comunidade passa a participar do problema.

O termo necessidades educativas especiais ainda não é uma unanimidade, e há discussão ao redor da terminologia adequada, tanto nas instituições oficiais de pesquisa, nas academias, quanto nos grupos de deficientes, passando pela necessidade contínua de revisão crítica da legislação sobre o assunto.

A legislação assinala para esta nomenclatura em educação inclusiva. Ainda, no ano de 1986 surgiutambémapropostadeintegraçãoeducativa, que representou um avanço significativo. O ensino dos alunos com necessidades educativas especiais poderia ser realizado no contexto da escola regular. Cardoso explicita que,

[...] esta nova concepção não nega que os alunos tenham problemas em seu desenvolvimento. No entanto, a ênfase consiste em oferecer ao aluno uma mediação. A finalidade primordial é analisar o potencial de aprendizagem, como sujeito integrado em um sistema de ensino regular, avaliando ao mesmo tempo quais os recursos que necessita para que sua evolução seja satisfatória. 0 conceito necessidades educativas especiais remete às dificuldades de aprendizagem e também aos recursos educacionais necessários para atender essas necessidades e evitar dificuldades (CARDOSO, 2003, pp.19-20).

As pessoas com necessidades educativas especiais passam a ser vistas como cidadãs, com direitos e deveres de participação na sociedade. A educação de pessoas com necessidades educativas especiais trilhou um caminho que, em uma fase inicial foi eminentemente assistencial, até chegar ao que hoje se denomina de educação inclusiva.

No Brasil, mudanças começaram a ocorrer na nomenclatura: de alunos excepcionais alterou- 
se para alunos com necessidades educativas especiais, o que ocorreu em 1986, pela Portaria CENESP/MEC, n.69, ainda que efetivamente não houvesse um avanço expressivo na inserção desses alunos no ensino regular.

A Constituição Brasileira de 1988 também trata deste assunto. No capítulo III, da Educação, da Cultura e do Desporto, artigo 205, prescreve que "a educação é direito de todos e dever do Estado e da Família." Em seu artigo 208, prevê mais especificamente que "[...] o dever do Estado com a educação será efetivado mediante a garantia de: [...] atendimento educacional especializado, preferencialmente na rede regular de ensino" (BRASIL, 1988).

A Lei de Diretrizes e Bases da Educação Nacional (LDB) mais recente - Lei no. 9.394 de 20/12/1996 - conceitua e orienta a abordagem inclusiva para os sistemas regulares de ensino dando ênfase, no capítulo $V$, especialmente à Educação Especial. Referencia no artigo 59, que "[...] os sistemas de ensino assegurarão aos educandos com necessidades especiais: currículos, métodos, técnicas, recursos educativos e organização específica, para atender às suas necessidades" (BRASIL, 1996).

Anteriormente, no ano de 1994, mais precisamente em 10 de junho, na cidade de Salamanca, na Espanha, ocorreu a Conferência Mundial de Educação, patrocinada pelo governo espanhol e pela UNESCO, com representantes de 92 países e 25 organizações internacionais. Nesta conferência foi reafirmado o compromisso com a educação para todos e elaborada uma declaração, conhecida na história da educação como a Declaração de Salamanca, que apresenta metas de ação na sociedade e é considerada um marco na documentação em favor da educação inclusiva.

No entanto, é necessário refletir sobre as implicações da legislação, das políticas públicas de inclusão de alunos que apresentam necessidades educativas especiais. A legislação existe, mas a educação inclusiva baseia-se em fatores mais abrangentes do que somente os legislativos. Uma das questões centrais reside em como tornar compatível essa realidade heterogênea com os esquemas, as tradições e as inércias profissionais de alguns professores, bem como de setores da sociedade que ainda fundamentam suas práticas em modelos que não estão preparados para trabalhar a diversidade e a diferença. É sabido que a estrutura escolar foi historicamente construída obedecendo a critérios racionalistas, com base no conceito de normalidade, de forma que os alunos aptos a superar os obstáculos de apreensão dos conteúdos tivessem acesso aos níveis mais elevados de ensino. Nessa ordem, aqueles com ritmo mais lento ou diferenciado de aprendizagem, deveriam seguir por outros caminhos, segregados ou ignorados pelo sistema escolar.

Nessa perspectiva, a predominância de conteúdos eruditos e científicos vem reforçando a primazia da razão e do fazer técnico, em detrimento dos aspectos subjetivos e criativos das experiências dos alunos. Esse fato estabelece a manutenção de uma hierarquia de saberes que valorizam os alunos com ritmo acelerado de apreensão de conceitos científicos, favorecidos por seu meio social, cultural e econômico, reproduzindo e mantendo essa ordem. Inserem propostas de ensino, de vivências culturais a partir da perspectiva de homogeneização, ou então, mantém a segregação e o isolamento de pessoas com necessidades educativas especiais, sem uma leitura crítica da realidade. Tal estrutura visa beneficiar mais alguns segmentos da sociedade mantendo a maioria das pessoas com necessidades educativas especiais afastada do processo de interação escolar e social, bem do acesso aos meios e instituições de produção e de veiculação cultural.

A visão da escola inclusiva impõe a demolição dos discursos educacionais que excluem as diferenças. A fronteira que separa de forma nítida aqueles olhares que continuam pensando que o problema da educação escolar está na anormalidade, no anormal, bem como daqueles que pensam o oposto: os que consideram a normalidade, a norma, o normal como o problema em questão é que deveria ser colocado sob suspeita. Trata-se de representações que se apresentam como científicas e acadêmicas, vigiando cada desvio, descrevendo cada detalhe das patologias, cada vestígio da normalidade, suspeitando de toda deficiência com a conhecida afirmação de que "algo está errado no sujeito, 
que possuir uma deficiência é um problema" (SKLIAR, 2003, p.18).

Essas considerações remetem-nos a lançar outros olhares, talvez menos vigilantes, que tenham de inverter a discussão, fazendo do normal, da norma o problema que deve ser colocado em questão. Esses olhares têm muito a oferecer à educação em geral, produzindo a desmistificação do normal, questionando os parâmetros instalados em educação e na sociedade sobre o que deve ser correto. Podem solapar a pretensão altiva da normalização, que não é mais do que a violenta imposição de uma suposta identidade, única, fictícia e sem fissuras, daquilo que é pensado como o normal (SILVA, 1997; SKLIAR, 2003).

Normalizar significa escolher arbitrariamente uma identidade e fazer dela a única identidade possível, a única identidade considerada como verdadeira e adequada. Nessa perspectiva, as pessoas com necessidades educativas especiais não encontram um espaço de aceitação. No Brasil, com base na legislação, o ensino inclusivo despontou como realidade, trazendo em seu bojo tanto a aceitação das diferenças, quanto questionamentos sobre a capacitação dos professores, sobre os modelos de aprendizagem vigentes nas escolas, sobre a adequação das escolas, comotambém, sobreas responsabilidades das famílias e da sociedade nesse processo.

As pesquisas do sociólogo e crítico Pierre Bourdieu (2004) demonstraram que a escola não consegue corrigir as desigualdades sociais. Ao contrário, ela acaba contribuindo para que essas desigualdades se repitam quando privilegia os herdeiros, ou seja, aqueles que a socialização familiar já preparou para o ensino (BOURDIEU, 1970).

O processo de superação desse modelo implica em se desestabilizar os parâmetros até então tidos como formadores desse habitus e apontar para outro horizonte, no qual as capacidades de desenvolvimento possam ser ampliadas a partir de novas percepções do sujeito escolar.

O movimento impulsionado pela Declaração Mundial de Educação para todos (1990) tem desencadeado mudanças legais e novas abordagens pedagógicas, que contemplam a inclusão em educação e a construção de novas estratégias pedagógicas que possam refletir a diversidade.

De acordo com Marie Duru-Bellat, socióloga e pesquisadora do Instituto de Pesquisa sobre Economia e Educação da França, a escola não é a "todo-poderosa", capaz de lutar contra as desigualdades sociais, sexuais e culturais, pois "[...] faz parte de uma sociedade na qual existem desigualdades do início ao fim". As desigualdades escolares consolidam-se precocemente, pois estão sujeitas às desigualdades materiais e culturais que estratificam os diferentes meios familiares. "A heterogeneidade representa um vetor de igualdade." As turmas heterogêneas favorecem mais o sucesso escolar de todos os alunos, evitando a estigmatização das turmas, os comportamentos negativos, como desvios de conduta, violência, exclusão, dentre outras (DURU-BELLAT, 2004, p. 22-23).

A função da escola, em muitos casos é a repetição do status quo existente fora de seus muros, na sociedade. Manter o status quo seria o que Mclaren chama de currículo oculto "[...] que desobriga o professor da necessidade de engajamento num auto-escrutínio pedagógico ou em qualquer crítica séria de seu papel na escola, e da escola na sociedade em geral" (MCLAREN, 1997, p. 242). É impossível pensar um sistema educativo inclusivo, para o qual as políticas públicas assinalam, mantendo o mesmo sistema inalterado. Para corresponder às diversas necessidades educacionais, os diferentes ritmos de aprendizagem, é imprescindível uma reestruturação sócio-educativa, com propostas curriculares apropriadas e adaptadas para a diversidade, mudanças organizacionais, estratégias didático-pedagógicas, recursos diferenciados, estruturação do espaço físico, capacitação docente. Implica também, em problematizar o que realmente significa aprender.

Trata-se de um processo mais amplo, que requer mudança de paradigmas, movimento, busca de aproximações com linguagens contemporâneas, com novos domínios, novas mídias; transformações nas práticas e de ensino, com reconhecimento de representações culturais. Implica em não perder de vista o caráter provisório do conhecimento, suas 
possibilidades emancipatórias e democratizantes, que incluem considerações sobre distintos contextos sociais. A interlocução é a chave para abrir portas na subjetividade conformista, ao insistir que os homens são essencialmente sujeitos de comunicação (FREIRE, 1971).

Freire(1982) trabalhou dialeticamente o ensinar e o aprender. Criou o neologismo "dodiscência", unindo docência e discência, como, muitos anos antes, Vygotsky criou o termo "obuclênia", que significa ensinar e aprender ao mesmo tempo e que, mais recentemente foi retomado em uma de suas obras traduzidas (VYGOTSKY, 2005).

Como sintetizou Freire (1983) quem ensina aprende ao ensinar e quem aprende ensina a aprender. Introduziu a idéia de re-aprender, destacando ainda que não se trata apenas de aprender a aprender, a fazer, a conviver. Trata-se também de "aprender porquê". Nesse princípio, Freire propôs uma mudança de paradigma, considerando todos os seres humanos incompletos e inacabados: completamse convivendo com os outros. Conscientes desse processo, seres humanos são movidos pela esperança, necessitam do sonho e da utopia para viver plenamente (FREIRE, 1977).

Vygotsky, expoente do Sócio-Interacionismo, postula que o professor deve ser um mediador entre o sujeito que aprende e o conhecimento, "mediar consiste nas ações de um agente intermediário em uma relação. A relação homem-mundo não é uma relação direta, mas fundamentalmente mediada" (VYGOTSKY, 1984, p.127).

Ao longo do processo de desenvolvimento, o ser humano deixa de necessitar das marcas externas e passa a utilizar signos internos, o que implica no processo de internalização. A partir do contato com os objetos e eventos sociais, a internalização dos mesmos passa a substitui-los, criando representações, mobilizando processos criativos, que possibilitam aprendizagens (VYGOTSKY, 1984, p.55).

Essas proposições teóricas, dentre outras são relevantes diante dos novos desafios decorrentes da legislação e das políticas públicas vigentes sobre a educação inclusiva. Nas diferentes áreas do conhecimento estamos diante de grandes transformações educacionais: mudanças nos parâmetros curriculares nacionais, na legislação referente à acessibilidade à escola, mudanças na obrigatoriedade do ensino, na fundação de um outro tipo de ensino e de escola, que se pretende inclusiva e que, no Brasil, por força de lei recebe essa denominação. Existe o direito universal à educação e as escolas brasileiras têm a obrigatoriedade legal de acolher a todos. Entretanto, se existe alguma coisa que pode ser nomeada como mudança no cenário atual da educação e do ensino, em diferentes áreas, isso não se refere apenas à nomenclatura, nem somente à legislação. Essa mudança relaciona-se com a possibilidade de questionar modelos, argumentos, paradigmas e de propor outros novos, originais, impensáveis até o momento. A pesquisa sobre os temas em questão insere-se nessa trama complexa, e não se concebe o ensino e a aprendizagem diante de tantos desafios dissociados da pesquisa.

A educação inclusiva prevê a inserção de indivíduos em classes regulares, independentemente de suas condições físicas, cognitivas, sensoriais, origem socioeconômica, raça ou religião. Este aprender juntos implica levar em consideração o contexto histórico-cultural e social em que estão inseridos. A idéia de ser humano imerso num contexto social como tendo corpo e mente, enquanto ser biológico e social, como membro da espécie humana e participante de um processo histórico, conjuga com a concepção histórico-cultural (OLIVEIRA, 2005).

A imagem de uma sala de aula homogênea, sem diferenças não corresponde à realidade da sociedade e sim a uma ideologia autoritária que vai destruindo e segregando o que não é dominante. Descobrir esta educação atenta aos direitos humanos e que coincide com a legislação referida, como a Declaração de Salamanca, o Fórum Mundial de Educação do Senegal, Dakar, também a Constituição do Brasil de 1988, a Lei de Diretrizes e Bases da Educação Nacional, que afirmam que os sistemas de ensino devem assegurar aos alunos com necessidades educativas especiais currículos, métodos e técnicas, recursos educativos e organização específica, para atender às suas necessidades.

Implementar e manter a educação inclusiva carrega em seu bojo a necessidade de mergulhar 
na educação em toda a sua complexidade, em toda sua rica variedade, em conhecer o outro, desfazendoidéias preconcebidas e discriminação impensada e ver a heterogeneidade como algo rico e valioso: "Opor a aventura da diferença, a curiosidade intelectual, à monotonia de um padrão único é uma atração no aprendizado" (MINDLIN, 1998, p.12).

Estas afirmativas coincidem com a Declaração de Salamanca na qual consta que as "escolas regulares com orientação para a educação inclusiva permitem uma real educação para todos" (DECLARAÇÃO DE SALAMANCA, 1994, p.9).

Falar em inclusão é falar de multiplicidade, de diversidade, de integração. A interação social é essencial nesta dinâmica, uma vez que favorece aprendizagens significativas e a expressão de múltiplas linguagens: verbal, corporal, bem como a afetividade, a criatividade a imaginação que, segundo teóricos como Piaget, Vygotsky, Wallon, dentre outros, constituem funções mentais superiores, tipicamente humanas (LA TAILLE, 1996).

Para Vygotsky (2003, p.53) o exercício pleno da criatividade está intimamente relacionado com a aprendizagem: "Nunca foi tão importante criar como em nossos tempos. Os mecanismos de controle não são fixos e padronizados, mas sim oscilantes e difusos, exigindo estratégias de enfrentamento capazes de ensejar múltiplas ações".

Estas estratégias de enfrentamento carregam em seu bojo a importância do reconhecimento do outro, o respeito, a tolerância. Para ampliar a reflexão aponta-se: essas questões são reais, ou trata-se de mais uma oposição binária entre inclusão e exclusão?

O que ocorre em nossos tempos é que alguns matizes de diferenças atéaqui ignorados, ou ocultos tem sido repensados, pelo menos não negados, talvez porque a legislação tenha estabelecido critérios mais rigorosos, ou por outras razões. As formas de diferenças do corpo, de aprendizagem, de linguagem, de movimento, de ser, de vestirse, de viver, devem ser vistas não como um atributo, uma propriedade, uma característica dos chamados de diferentes, mas como uma possibilidade de ampliar a compreensão acerca da intensidade das diferenças humanas.
Desse modo, pessoas com necessidades educativas especiais necessitam de ações mediadas, dos agentes mediadores, da postura de mediação do professor, da família, dos agentes culturais, sempre em interação com pessoas sem necessidades educativas especiais. Na medida em que esse processo se consolida, pessoas sem necessidades educativas especiais tornam-se também mediadores e o processo se reconfigura. Trata-se de novos tempos, que exigem outras posturas, nas quais a interação social é imprescindível. Mas, essa proposta pressupõe uma dinâmica de aceitação de diferenças, em uma postura ética solidária (SKLIAR, 2003).

Larrosa e Skliar (2002) sugerem uma pedagogia do diálogo, da harmonia, da empatia, não para terminar com as diferenças, mas para manter a tensão entre elas, compreendendo que é da tensão que emerge a criação de algo novo e a possibilidade de uma nova ordem, que subverte o caos. Não se trata de caracterizar o que é a diversidade e quem a compõe, mas sim de compreender melhor como as diferenças constituem seres humanos.

Morin (2000) descreve que as interações entre indivíduos produzem a sociedade que, por sua vez, testemunha o surgimento da cultura e que retroage sobre os indivíduos pela cultura. Para as instituições, essas afirmativas devem conduzir ao reconhecimento e à legitimação de novas práticas, reconhecendo e respondendo às necessidades diversificadas das pessoas, acomodando os diferentes estilos e ritmos de aprendizagem. Longe de tratar-se de um problema específico da pedagogia, refere-se a todas as áreas do conhecimento e dilui-se pelas malhas da rede social.

$\mathrm{Na}$ realidade, as pessoas com necessidades educativas especiais não podem ser descritas em termos de melhor e/ou pior, bem ou mal, superior ou inferior, maioria ou minoria, dentre outras considerações. $O$ fato de assinalar algumas necessidades educativas especiais como sendo diferenças volta a posicionar essas marcas, essas identidades como sendo opostas à idéia de norma, do normal e, então, daquilo que é pensado e fabricado como o correto, o positivo, o melhor (RODRIGUES, 2006). 
Nessa perspectiva, cabe aos pesquisadores e estudiosos de diferentes áreas do conhecimento questionar se o sistema tem tentado discutir a questão do outro nas políticas inclusivas, ou se o que preocupa é a obsessão pelo outro. Não parece um exagero afirmar que a escola atual ainda não se preocupa genuinamente com o outro, mas tem se tornado muitas vezes obsessiva diante de cada fragmento da diferença em relação à mesmice.

Se o conhecimento é múltiplo, variado, não estanque; se o processo de transmissão de ensinamentos não fica restrito às escolas é de grande importância que se repense também a formação de professores em diferentes níveis, para atuar no contexto dessa sociedade do conhecimento. É fundamental que sejam planejados processos formativos preparando o educador para uma atitude aberta frente ao e no mundo, pronto para aceitar o novo e a promovêlo, ajudando a desenvolver nas pessoas com quem se relaciona um processo de subjetivação autônomo e singular. Em outras palavras, o educador deve estar preparado para o principal desafio que se lhe coloca hoje, que se denomina como produzir novas potencialidades

É uma possibilidade que se abre para o desenvolvimento e para o benefício de todos, com ou sem necessidades especiais, nas escolas e nas diferentes instituições trazendo consigo um conjunto de fatores, para que todos possam ser inseridos totalmente na sociedade em todos os seus segmentos: trabalho, lazer, saúde, dentre outros.

A inclusão se concilia com uma educação para todos e com um ensino especializado ao aluno, mas não se consegue implantar essa opção de inserção sem enfrentar um desafio ainda maior: o que recai sobre o fator humano. Os recursos físicos e os meios materiais para a efetivação de um processo inclusivo de qualidade cedem um espaço de prioridade para o desenvolvimento de novas atitudes e formas de interação na vida em sociedade, exigindo uma nova postura diante da aceitação das diferenças individuais, da valorização de cada pessoa, da convivência na diversidade humana e da aprendizagem por meio da cooperação. Essas iniciativas promovem a adaptação das pessoas, com e sem necessidades educativas especiais, enfatizando as interações sociais e a aprendizagem por meio da cooperação, na qual professores são mediadores.

Uma das questões centrais que determina mudanças nada mais é do que a evidência do surgimento de novas luzes no bojo do desenvolvimento da humanidade, impregnada pela inclusão do tempo, da história e do sujeito como ator e construtor, precipitando crises conceituais. Tratase de criticar sistemas de determinação, teorias e, pela própria impotência em satisfazer a realidade, o estabelecimento de caminhadas em direção a novas propostas, novas perspectivas.

\section{Considerações Finais}

O processo de desenvolvimento dos seres humanos segueaaprendizagem, mas vaialém dela, ativando potenciais humanos. "A aprendizagem e o desenvolvimento, ainda que diretamente ligados não se processam simetricamente. O desenvolvimento não é estanque, nem acompanha a aprendizagem como uma sombra acompanha o objeto que a projeta" (VYGOTSKY, 1984, p.79).

Existe uma dependência recíproca, complexa e dinâmica, que não pode ser explicada por uma única fórmula especulativa, nem apriorística. Para Vygotsky $(1984 ; 1987$; 2003) a interação social é fundamental no desenvolvimento humano e na aprendizagem. Com base nessa afirmativa, a avaliação não pode ser definida de modo estanque, a priori, fechada em si mesma. A avaliação está integrada ao currículo e não pode ser dissociada do projeto educativo em sua totalidade, incluindo as políticas públicas, os projetos escolares, as propostas implícitas e a diversidade sócio-educacional.

A abertura das escolas para as diferenças tem a ver, dentre outras questões, com uma mudança radical nos processos de ensino e aprendizagem. Inclui uma proposta de ruptura entre as fronteiras existentes em diferentes disciplinas, entre saber e realidade. Isso implica em uma valorização da multiplicidade, da integração de saberes, das redes de conhecimento que, a partir daí se formam e se constituem e que se inserem também nas novas tecnologias da informação. Assinala para a transversalidade das áreas curriculares e para a autonomia intelectual do aluno, autor do 
conhecimento e que, por isso mesmo, imprime valor ao que constrói. Esse processo não pode prescindir da interação social.

Vygotsky (1987) afirma que existe uma interação entre o sujeito e o ambiente no processo de construção do conhecimento. Não se apreende a realidade diretamente, mas por reconstrução. Ensinar é, então, muito mais do que transmitir informações. Implica em mobilizar nos educandos o prazer de aprender. Avaliar é muito mais do que simplesmente medir e comparar: implica em integrar, promover ações interativas e adaptativas a todas as crianças.

A educação inclusiva é uma possibilidade de romper as barreiras que inviabilizam a aceitação das diferenças entre as pessoas. Mas, trata-se de um processo complexo, que exige capacitação, exercício da tolerância, conhecimento e que também necessita de avaliação permanente.

Diferentes terminologias percorrem hoje a trajetória rumo à diversidade, o que se presentifica na educação inclusiva. Implica, no entanto, que cada país deve definir e adotar políticas públicas pensadas desdesua própria realidade, apropriadas ao contexto, à sociedade e à cultura, e o processo de avaliação não pode ser dissociado desses princípios norteadores. A educação inclusiva de qualidade, que vise realmente integrar diferenças deve convocar os governantes, os professores, as famílias e a sociedade como parceiros diante desses desafios. Mais do que isso: trata-se da necessidade de rever paradigmas, de analisar a legislação, de conhecer e contextualizar políticas públicas contemporâneas.

Questões inclusivas, sociais e educacionais presentes na complexa dinâmica que caracteriza o ensino, a aprendizagem e a vida em sociedade pedem por novos olhares: olhares múltiplos para romper com a hegemonia epistêmica dos grandes saberes, contemplando a busca de olhares iluminados por novos focos e instrumentos que possam descer fundo na ordem implícita, penetrando no subjacente e no subjetivo. Trata-se de uma visão de escuta das vozes de uma ciência que, em sua busca transdisciplinar é capaz de gestar o novo em um movimento de olhar para o ensino e para a aprendizagem sob novos ângulos. Não há um modelo único para ensinar, assim como nem todos os seres humanos apresentam ritmos idênticos para aprender. Ainda, há aprendizagens distintas, assim como cada ser humano é diferente do outro. Uma visão hegemônica de ensino, na qual todas as crianças aprendem do mesmo modo e no mesmo ritmo é uma utopia, um contido expansivo, que não pode ser aprisionado por nenhuma ideologia, nenhuma legislação. A multiplicidade representa o convite para a coragem de espiar por frestas inusitadas e conseguir ver outras dimensões da realidade. Trata-se de uma subversão do olhar.

Morin (2000) descreve que as interações entre indivíduos produzem a sociedade que, por sua vez, testemunha o surgimento da cultura, e que retroage sobre os indivíduos pela cultura. Assinala queacomplexidadenãopoderiasercompreendida dissociada dos "elementos que constituem: todo o desenvolvimento verdadeiramente humano significa o desenvolvimento conjunto das autonomias individuais, das participações comunitárias e do sentimento de pertencer à espécie humana" (MORIN, 2000, p.52).

Para as escolas, essas afirmativas devem conduzir ao reconhecimento e à legitimação de novas práticas, reconhecendo e respondendo às necessidades diversificadas dos alunos, acomodando os diferentes estilos e ritmos de aprendizagem, assegurando uma educação de qualidade para todos. É uma possibilidade que se abre para o desenvolvimento e para o benefício de todos, com ou sem necessidades especiais, nas escolas e nas diferentes instituições, trazendo consigo um conjunto de fatores, para que todos possam ser inseridos totalmente na sociedade em todos os seus segmentos: cultura, trabalho, lazer, saúde.

A educação inclusiva propõe pensar a diferença como uma marca humana, presente em todas as situações sociais e, consequentemente, em todas as salas de aula, nos diversos níveis e modalidades de ensino e realidades sócio-culturais.

De acordo com Mantoan (2006, p. 192): “As diferenças são produzidas e não devem ser naturalizadas, como pensamos habitualmente. Essa produção é sustentada por relações de poder e merece ser compreendida, questionada e não apenas respeitada e tolerada". Para tanto, não basta aceitar a inclusão de pessoas com necessidades educativas especiais, uma vez que a hierarquia 
continua presente, em forma de generosidade ou benevolência para com aquele que é diferente.

Pensar a diferença é pensar nas relações estabelecidas entre os sujeitos da escola: quem são nossos alunos? Quais histórias trazem? Qual papel nós professores desempenhamos nessa mediação? Por quais caminhos podemos ensinar e como alunos com necessidades educativas especiais podem aprender? O desafio se coloca na mudança paradigmática, de modo a superar o habitus constituído e atingir o que se espera da escola inclusiva, o que, considerando as reflexões apresentadas, não pode ser respondido somente com base na legislação.

\section{Referências Bibliográficas}

BIANCHETTI, L. Aspectos Históricos da Educação Especial. Revista Brasileira de Educação Especial, Piracicaba, v.ll, n.3, p.7-19, 1995.

BORDIEU, P. A Economia das Trocas Simbólicas. São Paulo :Perspectiva, 2004.

BRASIL. Ministério da Educação e Cultura. Portaria CENESP/MEC, n. 69. Brasília, 1986.

BRASIL, Constithiçãa (1967). Constiuição da República Federativa do Brasil - 14 de Janeiro de 1967. Brasilia, DF: Fundação Projeto Rondon - Minter, 1986.

BRASIL. Constituição da República Federativa do Brasil. São Paulo: Atlas, 1988

BRASIL. Lei de Diretrizes e Bases da Educação Nacional. Lei n. 9394, de 20 de dezembro de 1996. D.0.U.de dezembro de 1996. Florianópolis: Sindicato das Escolas Particulares de Santa Catarina, 1996.

BRASIL. Boletim da UNESCO sobre Educação Inclusiva.Brasilia: Corde, 1998.

CARDOSO, M. Aspectos Históricos da Educação Especial: Da Exclusão à Inclusão - Uma Longa Caminhada. IN: MOSQUERA, J. M. e STOBAÜS, C. (Org.) Educação Especial: Em Direção à Educação Inclusiva. Porto Alegre: EDIPUCRS, 2003,P.15/26.

DECLARAÇÃO DE SALAMANCA E LINHA DE AÇÃO SOBRE NECESSIDADES EDUCATIVAS ESPECIAIS. Brasilia: Corde, 1994.

DINIZ, D. e GUILHELM, D. 0 que é Deficiência. São Paulo: Brasiliense, 2007.

DURU-BELLAT, M. Vencer 0 Grande Desafio da Igualdade de Oportunidades. Label-France: Revista do Ministério de Relações Exteriores. n.54, Abril-Junho 2004.

FREIRE, P. Educação como Prática e Liberdade. Rio de Janeiro: Paz e Terra, 1971.

FREIRE, P. Pedagogia da Autonomia: Saberes Necessários à Prática Pedagógica. Rio de Janeiro: Paz e Terra, 1977.

GUTIERREZ, F. Linguagem Total: Uma Pedagogia dos Meios de Comunicação. São Paulo: Summus, 1978.

LA TAILLE, Y. Piagey,Vygostky e Wallon :Abordagens Psicogenéticas em Discussão. São Paulo: Summus, 1996.

LARROSA, J. e SKLIAR, C. (Org). Habitantes de Babel. Política e Poética da Diferença. Belo Horizonte: Atlântica, 2002.

MANTOAN, M. T. 0 direito de ser, sendo diferente na escola. IN: RODRIGUES, D. (Org). Inclusão e Educação: Doze olhares sobre a Educação Inclusiva. São Paulo: Companhia das Letras, 2001. p.133-209.

MCLAREN, P. A Vida nas Escolas: Uma Introdução à Pedagogia Crítica nos Estados Unidos. Porto Alegre: ARTMED, 1997.

MORIN, E. Os Sete Saberes Necessários à Educação do Futuro. São Paulo: Cortez, 2000.

OLIVEIRA, M. K. Vygotsky: Aprendizado e Desenvolvimento-0 Processo Sócio-Histórico. São Paulo: Scipione, 2005.

RODRIGUES, D. Educação e Diferença: Valores e Práticas para uma Educação Inclusiva. Portugal: Porto, 2006.

SILVA, T. T. A Política e a Epistemologia do Corpo Normalizado. Rio de Janeiro: Espaço, 1997.

SKLIAR, C. E se o Outro não estivesse aí? Notas para uma Pedagogia (Improvável) da Diferença. Rio de Janeiro: DP\&A, 2003.

UNESCO. Declaração Mundial de Educação para Todos: Plano de Ação para satisfazer as necessidades básicas do aprendiz. Tailândia, 1990.

VYGOTSKY, L. S. Psicologia Pedagógica. São Paulo: Martins Fontes, 1984.

VYGOTSKY, L. S. La Imaginación y la Arte en la Infancia. Espanha: Akal, 2003.

VYGOTSKY, L. S. Psicologia e Pedagogia: Bases do Desenvolvimento e Aprendizagem. São Paulo: Centauro, 2005. 